\title{
Influence of Epichloë bromicola endophytic fungi on secondary metabolites following alkali tolerance improvement in host, Hordeum bogdanii
}

\section{Dan Han (D1412694623@qq.com )}

Tarim University

\section{Kai Wang}

Tarim University

\section{Feng Long}

Tarim University

Wangbing Zhang

Tarim University

\section{Xiang Yao}

Institute of Botany Jiangsu Province and Chinese Academy of Sciences

\section{Shuihong Chen}

Tarim University

\section{Research Article}

Keywords: endophytic fungi, Hordeum bogdani, alkaline stress, secondary metabolite

Posted Date: November 23rd, 2021

DOI: https://doi.org/10.21203/rs.3.rs-1097685/v1

License: (1) This work is licensed under a Creative Commons Attribution 4.0 International License. Read Full License 


\section{Abstract}

Purpose: The aim of this study was to investigate how endophytic fungi affect secondary metabolites of $\mathrm{H}$. bogdanii under alkaline stress at different concentrations. It is currently unclear whether the mechanism via which endophytic fungi improve the alkali tolerance of Hordeum bogdanii affects secondary metabolites. Unveiling this knowledge is crucial for understanding the tolerance mechanism of $\mathrm{H}$. bogdanii to alkaline stress. Methods: Endophyte-infected (E+) and endophyte-free (E-) individuals of $\mathrm{H}$. bogdanii were used as materials in this study. Vermiculite was used for plant cultivation and was carried out in the laboratory. After mixed alkali stress treatment, the roots, stems, and leaves of the plants were collected to measure the indicators related to secondary metabolites. Results: The results showed that endophytic fungi significantly increased the contents of phosphorus, polyphenols, and alkaloids, and the activities of polyphenol oxidase and acid phosphatase, and significantly reduced flavonoid content. The content of polyphenols and alkaloids in stems, polyphenol oxidase activity in stems and leaves, and acid phosphatase activity in leaves were significantly affected. In general, endophytic fungi improved the alkali resistance of $\mathrm{H}$. bogdanii by improving the related indicators of secondary metabolites. Conclusions: The findings of this study may aid in amplifying the alkali resistance mechanism of endophytic fungi to $\mathrm{H}$. bogdanii as well as provide insights into improving the alkali resistance of other plants.

\section{Introduction}

Plant secondary metabolism is the result of plant adaptation to the ecological environment during long-term evolution (Wang et al. 2020). Plant secondary metabolites are diverse, with different properties. According to their chemical structures, they can be divided into phenols, terpenes, and nitrogen-containing organic compounds(Li et al.

2021). Secondary metabolites are natural compounds produced by plants and have a variety of physiological roles (Chen et al. 2009). Stress can significantly promote the synthesis of plant secondary metabolites, which participate in the coordination of the relationship between plants and their environments (Tu 2019). Secondary metabolites have been found to play an important role in drought and salt tolerance in plants (Ahmed et al. 2015). Endophytic fungi can produce a variety of alkaloids, including organic amines, pyrrolizidines, and ergot alkaloids (Xu et al. 2010). Endophytic fungi in gramineous plants can produce four major alkaloids (i.e., organic amines such as peramine, pyrrolizidines such as loline, indole diterpene derivatives such as lolitrem $B$, and ergot alkaloids such as ergovaline). These have various biological activities, such as resistance to pathogenic bacteria, resistance to nematodes, and enhancement of plant allelopathy.

Hordeum bogdanii is a wild gramineous grass distributed in Xinjiang, Gansu, Qinghai, Inner Mongolia, and other regions of China. It is an important wild germplasm resource and is used as forage grass. It has strong cold tolerance and saltalkali resistance, and plays an important role in the improvement of desertification and saline-alkali land (Jia 1987; Ma et al. 1998). The endophytic fungi of grasses are a large group that grow and complete all or most of their life cycle within plants, while the grasses do not show external symptoms (Gao et al. 2007; Bongiornoet al. 2016). The endophytic fungus and host coevolve and have a mutually beneficial relationship (Chen et al. 2017; Tanaka et al. 2012). Endophytic fungi obtain nutrients from the host grass, while simultaneously enhancing the resistance of the grass to biological and abiotic stresses, thereby promoting its ability to adapt to the environment. Examples of this include promoting growth, resisting harm by herbivores and nematodes (Kuldau and Bacon 2008; Behie et al. 2012), enhancing resistance to pathogenic fungi (Li et al. 2007; Xia et al. 2018), increase resistance to drought stress (Clay and Schardl 2002; Bu et al. 2018), salt stress, and tolerance (Song et al., 2015; Wang et al., 2019), which is often considered a defensive symbiosis (Clay 1999; Kauppinen et al. 2016). Some researchers have detected endophytic fungi $₫$ Neotyphodium $₫$ in $H$. bogdanii in western China (Li and Sun 1996, 1997; Nan 1996). In addition, a comparative study of $H$ bogdanii plants with endophytic fungi (E+) and without endophytic fungi (E-) in the Altai area of Xinjiang, China, showed that endophytic fungi promoted the growth of host $H$. bogdanii and increased tiller number, biomass, and the forage yield of plants (Nan 1996). 
Polyphenols are important, physiologically active, secondary metabolites involved in the regulation of growth, development, and response to adversity in plants. Studies have shown that the level of phenolic compounds in plants is significantly increased under a variety of biological or abiotic stresses (Chen 2020). Polyphenol oxidase activity is related to ear germination resistance (Huang et al. 2021). Flavonoids can be used as regulators in the process of plant growth and development and improve plant resistance to certain adverse stresses (Chu et al. 2007). Moreover, plant endophytic fungi can produce secondary metabolites, such as alkaloids and flavonoids (Su 2018).

However, little information is available on the effects of endophytic fungi on secondary metabolites under alkaline stress. Therefore, it is unclear if the mechanism of endophytic fungi improving the alkali tolerance of the host $H$. bogdanii affects the secondary metabolites. This knowledge is greatly significant for understanding the tolerance mechanism of $H$. bogdanii to alkaline stress. In this study, we examined the content of secondary metabolites and related enzymes involved in the process. Our findings will help to amplify the alkali resistance mechanism of endophytic fungi to $H$. bogdanii and supply a new field for exploring effective ways to improve the alkali resistance of plants.

\section{Materials And Methods}

\subsection{Plant material:}

The seeds of $H$. bogdanii were collected from Wensu County, Aksu District, Xinjiang Province, China $\left(80^{\circ} 76 \otimes \mathrm{E}, 41^{\circ} 58 \otimes \mathrm{N}, \mathrm{H}\right.$ $1514 \mathrm{~m})$. A E+ plant and half of its tillers were sterilized with fungicide to obtain homogenous plants without endophytic fungi (E-). The seeds of the E+ and E- plants bred in the field were used in this experiment. In the greenhouse of Tarim University (daytime temperature $25^{\circ} \mathrm{C}$, night temperature $15{ }^{\circ} \mathrm{C}, 14 \mathrm{~h}$ light per day), $\mathrm{E}+$ and $\mathrm{E}$ - $\mathrm{H}$. bogdanii grass were planted in plastic flowerpots (pot diameter $13 \mathrm{~cm}$, bottom diameter $8 \mathrm{~cm}$, height $12 \mathrm{~cm}$ ). Every week, $200 \mathrm{ml}$ of Hoagland nutrient solution was poured in each pot and plants were watered regularly. After the plants were cultured for 6 weeks, the endophytic fungi were detected under a microscope using the sheath aniline blue test method (Li et al. 2008), and the E+ and E- plants were determined again.

\subsection{Alkali stress treatment:}

With a $\mathrm{Na}_{2} \mathrm{CO}_{3}: \mathrm{NaHCO}_{3}$ ratio of $1: 1$, five concentrations of mixed alkali $(25,50,100,150$, and $200 \mathrm{mmol} / \mathrm{L})$ were used to treat $H$. bogdanii plants, with no added alkali as the control. Each treatment had five replicates. After 21 days of treatment, fresh plant root, stem, and leaf samples were collected and immediately frozen in a refrigerator at $-80{ }^{\circ} \mathrm{C}$. The remaining samples were dried, crushed, sieved, and stored at room temperature to determine the relevant indicators.

\subsection{Related physical and chemical index measurement methods:}

(1) Phosphorus content: using molybdenum antimony colorimetric method (Song et al. 2015; Liang et al. 2017).

(2) Polyphenol content: Folin-Ciocalteu method was used to determine the polyphenol content (Shi et al. 2018).

(3) Determination of polyphenol oxidase activity: refer to the colorimetric method of Li Zhongguang et al. (Shi et al. 2018).

(4) The contents of flavonoids and alkaloids, and acid phosphatase activity were measured using a kit from Suzhou Keming Biotechnology Co., Ltd.

\subsection{Data processing and statistical analysis methods}

All data in this paper were calculated by Excel 2016, mapped by Sigmaplot12.5, and Spss19 was used to analyze the significance of the difference. The effects of alkali treatment and endophytic fungi on the contents of phosphorus, polyphenols, flavonoids, and alkaloids, and the activities of polyphenol oxidase and acid phosphatase in $H$. bogdanii were 
detected by two-way ANOVA囚The effects of different alkali treatment concentrations on the contents of phosphorus, polyphenols, flavonoids, and alkaloids, and the activities of polyphenol oxidase and acid phosphatase in $\mathrm{H}$. bogdanii were detected by one-way ANOVA. An independent sample t-test was used to detect the differences in the contents of $\mathrm{E}+$ and $\mathrm{E}$ phosphorus, polyphenols, flavonoids, and alkaloids, and the activities of polyphenol oxidase and acid phosphatase at the same alkali concentration.

\section{Results}

\subsection{Effects of endophytic fungi on phosphorus content in roots of $H$. bogdanii under different concentrations of alkali stress}

Under the same treatment, the phosphorus content in the roots of plants with endophytic fungi $(\mathrm{E}+)$ was higher than that in the roots of plants without endophytic fungi (E-) (Figure 1). Although the phosphorus content in the roots of $\mathrm{E}+$ and $\mathrm{E}$ plants was not significantly different under the $200 \mathrm{mmol} / \mathrm{L}$ alkali treatment, the phosphorus content of E+ plants was significantly higher than that of E- plants in the other alkali treatments $(P<0.05)$. The phosphorus content in the roots of $H$. bogdanii plants reached the highest content at an alkali treatment concentration of $25 \mathrm{mmol} / \mathrm{L}$, which was significantly higher than the phosphorus content in the roots of the control plants and showed a significant decreasing trend as the alkali concentration increased $(P<0.05)$. From the two-factor ANOVA table (Table 1$)$, both endophytic fungi and alkali treatment significantly affected the phosphorus content in the roots of $H$. bogdanii, and there was an interaction between the endophytic fungi and alkali treatment.

Table 1 Two-factor analysis of endophytic fungi on the phosphorus content, flavonoids, and alkaloids of Hordeum bogdanii under alkali stress

\begin{tabular}{|c|c|c|c|c|c|c|c|}
\hline & \multicolumn{3}{|c|}{ Phosphorus content } & \multicolumn{2}{|c|}{ Flavonoid content } & \multicolumn{2}{|c|}{ Alkaloid content } \\
\hline & $\mathrm{df}$ & $\mathrm{F}$ & $P$ & $\mathrm{~F}$ & $P$ & $\mathrm{~F}$ & $P$ \\
\hline Endophytic Fungi & 1 & 409.034 & 0.000 & 114.922 & 0.000 & 1281.122 & 0.000 \\
\hline Alkali treatment & 5 & 3305.367 & 0.000 & 32.157 & 0.000 & 549.658 & 0.000 \\
\hline Endophytic Fungi $\times$ Alkali treatment & 5 & 68.466 & 0.000 & 6.634 & 0.001 & 31.433 & 0.000 \\
\hline
\end{tabular}

\subsection{Effects of endophytic fungi on flavonoids and polyphenols of $H$. bogdanii under different concentrations of alkali stress}

Under the same treatment, except for the high alkali concentration treatment of $200 \mathrm{mmol} / \mathrm{L}$, the content of flavonoids in the stems of E+ plants was significantly lower than that of E- (Figure 2). With an increase in alkali stress, flavonoid contents increase in $\mathrm{E}+$ plants. The flavonoid contents in the $\mathrm{E}+$ plants in the $150 \mathrm{mmol} / \mathrm{L}$ and $200 \mathrm{mmol} / \mathrm{L}$ treatments were the highest, and were significantly higher than that in the control. $(P<0.05)$. From the two-factor ANOVA (Table 1$)$, endophytic fungi and alkali treatment significantly affected the flavonoid content in $H$. bogdanii stems, and there was an interaction between endophytic fungi and alkali treatment $(P<0.05)$. 
Under the same treatment, the polyphenol content in $\mathrm{E}+H$. bogdanii stems was higher than that of $\mathrm{E}-$, and the difference was significant when alkali treatments were $100 \mathrm{mmol} / \mathrm{L}, 150 \mathrm{mmol} / \mathrm{L}$, and $200 \mathrm{mmol} / \mathrm{L}(P<0.05)$ (Figure 3A). The polyphenol content increased with an increase in the alkali treatment concentration, and the polyphenol content in the stem was the highest under the $200 \mathrm{mmol} / \mathrm{L}$ alkali treatment. Except for the $25 \mathrm{mmol} / \mathrm{L}$ treatment and the control, treatments were not significantly different. The polyphenol content in the stems of the other treatments were significantly higher than that of the control treatment.

Although there was no significant difference in polyphenol content between $\mathrm{E}+$ and $\mathrm{E}$ - roots in the $25 \mathrm{mmol} / \mathrm{L}$ treatment, in the other treatments, polyphenol content in $\mathrm{E}+$ plant roots was significantly higher than that in $\mathrm{E}$ - plants. $(P<0.05)$ (Figure 3B). The effect of alkali concentration stress in E+ roots first lead to an increase and then a decrease in polyphenol content. The polyphenol content was the highest at $150 \mathrm{mmol} / \mathrm{L}$, and the control was the lowest; the polyphenol content in E- root was also the lowest in the control treatment. Therefore, alkali stress also significantly affected the polyphenol content in the roots and stems of $\mathrm{H}$. bogdanii, and the results of the two-way ANOVA showed that both the endophytic fungi and alkali treatment significantly affected the content of polyphenols in the roots and stems of $H$. bogdanii, and that there was an interaction between the two $(P<0.05)$.

\subsection{Effects of endophytic fungi on alkaloids in the stems of $H$. bogdanii under different concentrations of alkali stress}

Under the same treatment, the alkaloid content of E+ plants was significantly higher than that of E- plants (Figure 4). With an increase in the alkali stress treatment concentration, the content of alkaloids in the stems of $\mathrm{H}$. bogdanii showed a significant downward trend. With an increase in the alkali treatment concentration, the alkaloid content of E+ stems was $22.9 \%, 24.6 \%, 20.8 \%, 20.1 \%, 9.7 \%$, and $8.8 \%$ higher than that of the E- stem under the same alkali stress. From the twofactor statistical analysis table (Table 1), both endophytic fungi and alkali treatment significantly affected the alkaloid content in stems, and there was an interaction between endophytic fungi and alkali treatment $(P<0.05)$.

\subsection{Effects of Endophytic Fungi on Enzyme Activities Related to Secondary Metabolites in Stems and Leaves of $H$. bogdanii under Different Concentrations of Alkaline Stress}

\subsubsection{Effects of endophytic fungi on acid phosphatase in leaves of $H$. bogdanii under different concentrations of alkali stress}

Under the same treatment, the acid phosphatase activity in the leaves of $\mathrm{E}+\mathrm{H}$. bogdanii plants was higher than that of $\mathrm{E}$ (Figure 5A). Except for the insignificant difference in the control, in all other treatments E+ were significantly higher than E$(P<0.05)$. Acid phosphatase activity showed a decreasing trend with increasing alkali stress concentration, and the alkali treatment was significantly lower than that of the control. From the two-factor analysis table (Table 2), it can be concluded that both endophytic fungi and alkali treatment significantly affected the acid phosphatase activity in $H$. bogdanii leaves $(P<0.05)$, and there was an interaction between the two $(P<0.05)$.

\subsubsection{Effects of endophytic fungi on polyphenol oxidase activity in stems and leaves of $H$. bogdanii under different levels of alkali stress}

Under the same treatment, the polyphenol oxidase activity in the stems and leaves of the E+ plants was significantly higher than that of the $\mathrm{E}$ - plants $(P<0.05)$ (Figure 5B and 5C). With an increase in the alkali treatment concentration, the activity of polyphenol oxidase in the stems and leaves of $H$. bogdani gradually decreased, and the difference between treatments was significant. As shown in Table 2, both endophytic fungi and alkali treatment significantly affected the polyphenol oxidase activity in the stems and leaves of $H$. bogdani, and there was an interaction between endophytic fungi and alkali treatment. 
Table 2 Two-factor analysis of effect of endophytic fungi on the polyphenol content, and the activities of polyphenol oxidase and acid phosphatase in Hordeum bogdanii under alkali stress

\begin{tabular}{|c|c|c|c|c|c|c|c|c|c|c|c|}
\hline & \multirow[b]{2}{*}{$\mathrm{df}$} & \multicolumn{2}{|c|}{$\begin{array}{c}\text { Polyphenol } \\
\text { content (stem) }\end{array}$} & \multicolumn{2}{|c|}{$\begin{array}{l}\text { Polyphenol } \\
\text { content (root) }\end{array}$} & \multicolumn{2}{|c|}{$\begin{array}{c}\text { Polyphenol } \\
\text { oxidase activity } \\
\text { (stem) }\end{array}$} & \multicolumn{2}{|c|}{$\begin{array}{c}\text { Polyphenol } \\
\text { oxidase activity } \\
\text { (leaf) }\end{array}$} & \multicolumn{2}{|c|}{$\begin{array}{l}\text { Acid } \\
\text { phosphatase } \\
\text { activity }\end{array}$} \\
\hline & & $\mathrm{F}$ & $P$ & $\mathrm{~F}$ & $P$ & $\mathrm{~F}$ & $P$ & $\mathrm{~F}$ & $P$ & $\mathrm{~F}$ & $P$ \\
\hline $\begin{array}{c}\text { Endophytic } \\
\text { Fungi }\end{array}$ & 1 & 74.062 & 0.000 & 584.955 & 0.000 & 1841.759 & 0.000 & 284.999 & 0.000 & 240.783 & 0.000 \\
\hline $\begin{array}{c}\text { Alkali } \\
\text { treatment }\end{array}$ & 5 & 161.645 & 0.000 & 186.247 & 0.000 & 3881.38 & 0.000 & 1465.891 & 0.000 & 576.207 & 0.000 \\
\hline $\begin{array}{l}\text { Endophytic } \\
\text { Fungi } \times \\
\text { Alkali } \\
\text { treatment }\end{array}$ & 5 & 6.593 & 0.000 & 49.902 & 0.000 & 420.888 & 0.000 & 8.817 & 0.000 & 12.002 & 0.000 \\
\hline
\end{tabular}

\section{Discussion}

Salt and alkalinity affect the physiological and metabolic pathways of plants, similar to other adverse factors. Adversity stress can significantly promote the synthesis of plant secondary metabolites. Secondary metabolism and its products are the material basis of plant response to environmental stress, and its content affects plant resistance to stress (Tu 2019). Polyphenols and flavonoids are important secondary metabolites of plants. To explore whether the mechanism via which endophytic fungi improve alkali tolerance of host $H$. bogdanii influences secondary metabolites, we investigate the contents of secondary metabolites and associated enzymes. In the present study, the infection of endophytic fungi and mixed alkali stress treatment on $\mathrm{H}$. bogdanii had significant effects on phosphorus content in roots, flavonoids and alkaloid content in stems, polyphenol content in roots and stems, acid phosphatase activity in leaves, and polyphenol oxidase activity in stems and leaves.

At a concentration of $25 \mathrm{mmol} / \mathrm{L}$, the phosphorus content in the roots of $\mathrm{E}+$ and $\mathrm{E}$ - plants both reached the highest value and was significantly higher than that of the control. The reason for this may be due to the growth-promoting effect of low alkali concentration, which caused the phosphorus content at this treatment to be significantly higher than that of the control. Li and Tian (2014) also showed that appropriate salt stress can promote the absorption of phosphorus by plants. Malinowski et al (2000) found that the accumulation of phosphorus in the roots and stems of tall Festuca (genotype DN2) E+ plants was significantly higher than that of E-plants. Acid phosphatase is an important enzyme that regulates phosphorus metabolism in organisms. Acid phosphatase not only participates in the growth and metabolism of organisms and signal transduction pathways, but also enhances plant resistance to phosphorus deficiency, drought, low temperature, water, salt, and other adversities. Wang et al (2015), Liu et al (2017), and Javot et al (2007) also proved that arbuscular mycorrhizal (AM) fungi can significantly promote the absorption of phosphorus by roots after infecting plants, stimulate the secretion and activity of plant phosphatase, and induce an increase in phosphorus content in roots. Xie et al (2013) also showed that the acid phosphatase activity of plants inoculated with endophytic fungi increased significantly 
and that the total phosphorus content also increased to a greater extent. The findings of this study also showed that endophytic fungi promoted acid phosphatase activity in $\mathrm{H}$. bogdanii leaves, which promoted an increase in phosphorus content. This difference was more obvious under alkaline stress; as the alkali concentration increased both the phosphorus content and acid phosphatase activity showed a downward trend.

Plant polyphenols are an inherent component of many plants. Under normal conditions, their content in plants is very low, but when plants are stimulated by foreign factors, the content of these substances will increase significantly to enhance the resistance to abiotic stress (Zhao 2004). Studies have shown that the content of polyphenols in plants can increase under adverse conditions (Wang et al. 2007). Phenolic compounds play a vital role in relieving oxidative stress because they are involved in the detoxification of reactive oxygen species (Wang et al. 2011). It has been reported that in several other grasses, endophytic fungal infection increases the content of phenolic compounds in plant roots (Ponce et al. 2009; Vázquez- de-Aldana et al. 2011). The present study also showed that with an increase in alkali stress concentration, the content of polyphenols in the roots and stems of $H$. bogdanii showed an increasing trend, especially in the stems. The content of polyphenols in E+ plants was higher than in E- plants. The study also showed that endophytic fungi increase the polyphenol content in the host $H$. bogdanii stem under alkali stress, which help the host to resist alkali stress.

Under alkaline stress, the polyphenol oxidase activity of $H$. bogdanii gradually decreased with the increase in alkali concentration. However, the E+ plant was significantly higher than E-, and the control E+ was also significantly higher than E-. Previous studies have shown that low concentrations of saline alkali stress can promote polyphenol oxidase activity. Yan et al (2021) and Zhao et al (2005) believe that the more alkaline the environment, the faster the enzyme activity decreases. This is consistent with the results of the trend of polyphenol oxidase activity in the stems and leaves of $H$. bogdanii obtained in the present study. Moreover, studies have also shown that when the activity of polyphenol oxidase decreases, the enzymatic reaction is inhibited, leading to an increase in polyphenol content (Zhang et al. 2013). The results of the present study also showed that under high alkali concentrations, the activity of polyphenol oxidase decreased and polyphenol content increased.

Under different concentrations of alkali stress, endophytic fungi had a significant effect on the alkaloid content in the stems of $H$. bogdanii. Alkali treatment reduced the alkaloid content of $H$. bogdanii. It has been reported that the total alkaloid content of plants decreases with an increase in $\mathrm{pH}$ (Tang and Chen 2011), which is consistent with the results of the present study. The alkaloid content of E+ plants was significantly higher than that of E- plants. Gao and Nan (2007) believed that endophytic fungi can significantly increase the alkaloid content of plants, which is consistent with this result.

Under different concentrations of alkali stress, endophytic fungi had a significant effect on the flavonoid content in the stems of $\mathrm{H}$. bogdanii. The flavonoid content in E+ plants was significantly lower than that in E-plants, and the content of flavonoids in high alkali concentrations was significantly higher than that in low alkali concentrations. Chen (2019) suggested that endophytic fungal infection significantly reduced the content of flavonoids in $H$. bogdanii, and the results are similar to those of the present study; salt stress increases the total flavonoid content in roots, stems, leaves, and flowers (Yan 2011; Hou et al. 2016). Other studies (Zhou et al. 2004) showed that flavonoids accumulate under stress. In this experiment, as the alkali concentration increased, the flavonoid content increased, and the high alkali concentration flavonoid content was significantly higher than the low alkali concentration. This result is similar to that of salt stress, indicating that both salt and alkali stress can increase flavonoid content.

Latch et al (1985) suggested that the increase in plant biomass of ryegrass infected with endophytic fungi may be related to gibberellin (GA). Wang et al (2007) reported that gibberellin can inhibit the synthesis of flavonoids by reducing the activity of chalcone synthase (CHS). In the present study, we measured the hormones of $\mathrm{E}+$ and E- plants of Burton barley and found that the content of gibberellin GA3 in E + leaves of H. bogdanii, planted indoors and outdoors, was higher than 
that of E - (data to be published). The higher the content of GA3, the more it inhibited the content of flavonoids, which was consistent with the result that the content of flavonoids in $\mathrm{E}+$ plants was significantly lower than that of E-.

Alkaloids are N-based secondary metabolites, and flavonoids are C-based secondary metabolites. According to the hypothesis of "carbon nutrient balance" proposed by Bryant et al (1983), there is a balance between C-based secondary metabolites (such as terpenes and phenols) and N-based secondary metabolites (such as alkaloids). In the present study, endophytic fungi significantly promoted the content of $\mathrm{N}$-based secondary metabolites alkaloids, but significantly reduced the content of C-based secondary metabolites flavonoids to maintain the nutrient balance in the plant. The experimental results also align with the "carbon nutrient balance" hypothesis.

In summary, endophytic fungi promote the increase of phosphorus content by promoting acid phosphatase activity in plant leaves, and the effect is more significant under alkali stress. Endophytic fungi increased plant polyphenol content and polyphenol oxidase activity under alkali stress, and plant polyphenol oxidase activity decreased gradually with an increase in alkali concentration. Endophytic fungi could significantly increase alkaloid content in plants, but alkali treatment decreased alkaloid content in plants. With an increase of alkali concentration, flavonoid content increased, and flavonoid contents under high alkali concentrations were significantly higher those under low alkali concentrations. However, endophytic fungi decreased the content of plant flavonoids. Endophytic fungi could have significantly promoted the alkaloid contents of secondary metabolites, based on $\mathrm{N}$, and significantly reduced flavone contents, based on carbon, as a strategy of maintaining nutritional balance in plants.

Therefore, the mechanism via which endophytic fungi improve alkali tolerance of host plants influences secondary metabolites. Endophytic fungi can improve the alkali resistance of host plants by increasing the contents of secondary metabolites, polyphenols and alkaloids, and enhancing polyphenol oxidase and acid phosphatase activities, which in turn increase phosphorus contents in plants. The results of the present study could facilitate the enhancement of alkali tolerance in plants.

\section{Declarations}

\section{Competing Interests}

This study was funded by Nation Science Foundation Project(31802132ه31660689).

The authors have no relevant financial or non-financial interests to disclose.

The authors have no conflicts of interest to declare that are relevant to the content of this article.

All authors certify that they have no affiliations with or involvement in any organization or entity with any financial interest or non-financial interest in the subject matter or materials discussed in this manuscript.

The authors have no financial or proprietary interests in any material discussed in this article.

\section{Acknowledgements}

Thank my mentor Chen shuihong for giving me the fund support and writing guidance for this article, and thank all the authors of the article for cooperating with me to complete this experiment.

\section{References}

1. AhmedI M, Nadira UA, Bibi N, Cao F, He X, Zhang G, Wu FB (2015) Secondary metabolism and antioxidants are involved in the tolerance to drought and salinity, separately and combined, in Tibetan wild barley[J]. Environmental \& 
Experimental Botany 111:1-12

2. Bongiorno VA, Rhoden SA, Garcia A, Polonio JC,Azevedo JL,Pereira JO,Pamphile JA (2016) Genetic diversity of endophytic fungi from Coffea arabica cv. IAPAR-59 in organic crops.Annals of Microbiology 66:855-865

3. Behi SW, Zelisko PM (2012) Bidochka MJEndophytic insect-parasitic fungi translocate nitrogen directly from insects to plants.Science 336(6088): 1576

4. Bryant JP, Chapin FSIII,Klein DR (1983) Carbon/nutrient balance of boreal plants in relation to vertebrate herbivory[J].Oikos 40:357-368

5. Chen F, Liu C-J, Tschaplinski TJ,Zhao N (2009) Genomics of secondary metabolism in populus: interactions with biotic and abiotic environments. Crit Rev Plant Sci 28:375-392

6. Chen SH, Cao Y, Chen TX,Li CJ (2018) )Research Process the Endophyte Improving the Grass's Salt and Alkali Resistance. Biotechnology Bulletin 33(12):1-6

7. Chen SH, Chen TXYaoX, Lv H, Li CJ (2018) Physicochemical properties of an asexual Epichloë endophyte-modified wild barley in the presence of salt stress. Pak J Bot 50(6):2105-2111on

8. Clay K (1999) Fungal endophyte symbiosis and plant diversity in successional fields.Science 285(5434):1742-1744

9. Chen $Y(2020)$ The root polyphenol in response to aluminum stress and its mechanism in mediating aluminum tolerance in lettuce.Thesis Zhejiang University Zhejiang-450000 chinapp7-12

10. Chu h,Hu HY, Lu CY, Li X (2007) Research Progress on metabolism and regulation of flavonoids in plants[J].Journal of Xiamen University(Natural Science Edition) (S1):136-143

11. Chen TX (2019) Physiological Mechanism of Epichloë Endophyte Infection to Enhance Salt Tolerance of Wild Barley.Thesis Lanzhou University Lanzhou-730020 chinapp122-123

12. Gao JH, Nan ZB (2007) A review of bioprotective alkaloids of grass-fungal endophyte symbioses. J Ecol 27(6):25312533

13. Hou LL, Yang XB,Dong XN, Ding MQ, Zhu XM,Shao JR (2016) Effects of stress on total flavonoids content and key enzyme gene expression in Tartary Buckwheat at flowering stage[J]. Journal of Nuclear Agricultural Sciences 30(01):184-192

14. Huang YW, Dai XR,Liu WH,Yang L, Mai CY,Yu LQ,Yu GJ, Zhang HJ, Li HJ,Zhou Y (2021) Relationship between the allelic variations at the Ppo-A1 and Ppo-D1 loci and pre-harvest sprouting resistance in wheat[J/OL].Journal of crops:1-12

15. Jia SX (1987) Flora of forage plants of ChinaVolume I.Beijing: Agricultural Press 124-127

16. Javot H Pumplin N,Harrison MJPhosphate in the arbuscular mycorrhizal symbiosis: transport properties and regulatory roles.Plant Cell \& Environment200730(3):310-322

17. Kuldau G, Bacon C (2008) Clavicipitaceous endophytes: Their ability to enhance resistance of grasses to multiple stresses. Biol Control 46(1):1-71

18. Kauppinen M, Saikkonen K, Helander M et al (2016) )Epichloë grass endophytes in sustainable agriculture.Nature Plants(2):15224

19. Latch GCM, Hunt WF, Musgrave DR (1985) Endophytic fungi affect growth of perennial ryegrass[J]. New Zealand Journal of Agricultural Research 28(1):165-168

20. Li BJ, Sun CS (1996) Investigation of Gramineae in Northwest China. Grassland in China 2:29-32

21. Li BJ, Sun CS (1997) Investigation of Gramineae in Northwest China. Grassland in China 3:69-71

22. Li CJ, Nan ZB,Liu Y, Volk H, Paul Dapprich, Peter (2008) Study on detection method of endophytic fungi in drunken horse grass.Annual meeting of Chinese society of Plant Pathology

23. Li JN, Tian XP (2014) Study on the relationship between phosphorus uptake of maize and inorganic phosphorus stress. Soil Bulletin 45(04):984-989

Page 9/15 
24. Liu CY, Wu QS,Zhou YN (2017) Effects of arbuscular mycorrhizal fungi on phosphorous uptake and phosphatase release in trifoliate orange seedlings. Acta mycologica Sinica2017 36(07):942-949

25. Liang Y, Wang HC,Li CJ, Nan ZB,Li FDEffects of feeding drunken horse grass infected with Epichloë gansuensis endophyte on animal performance clinical symptoms and physiological parameters in sheep.Bmc Veterinary Research13(1):223-229

26. Li MJ, Hu T,Pan SY (2021) Effects of food system composition and processing methods on bioavailability of plant secondary metabolites[J/OL].food science:1-14

27. Ma RC, Zhang HS, Mu LT,Song SJ (1998) Hordeum bogdanii Wilensky regional experiment.Journal of Xinjiang Agricultural University(04):35-38

28. Malinowski DP, Alloush GA,Belesky DP (2000) Leaf endophyte Neotyphodium coenophialum modifies mineral uptake in tall fescue[J]. Plant \& Soil 227(1-2):115-126

29. Malinowski DP, Belesky DP (2019) )Epichloë (formerly Neotyphodium) fungal endophytes increase adaptation of cool-season perennial grasses to environmental stresses[J].Acta Agrobotanica72(2)

30. Nan ZB (1996) Effects of Endophytic Fungi on growth of Hordeum bogdanii Wilensky.Pratacultural Science(01):1618

31. Ponce MA, Bompadre MJ, Scervino JM et al (2009) Flavonoids benzoic acids and cinnamic acids isolated from shoots and roots of Italian rye grass (Lolium multiflorum Lam) with and without endophyte association and arbuscular mycorrhizal fungus[J]. Biochemical Systematics \& Ecology 37(4):245-253

32. Swarthout D, Harper E, Judd S, Gonthier D,Shyne R, Stowe T,Bultman T (2009) Measures of leaf-level water-use efficiency in drought stressed endophyte infected and non-infected tall fescue grasses[J]. Environ Exp Bot 66(1):8893

33. Song ML, Chai Q, Li XZ et al (2015) An asexual Epichloë endophyte modifies the nutrient stoichiometry of wild barley (Hordeum brevisubulatum)under salt stress. Plant Soil 387(1-2):153-165

34. Song ML, Li XZ, Saikkonen K, Li CJ, Nan ZB (2015) An asexual Epichloë endophyte enhances waterlogging tolerance of Hordeum brevisubulatum. Fungal Ecology 13:44-52

35. Su TJ (2018) Biological activities of endophytic fungi and their metabolites from the original plants of FRITILLARIAE CIRRHOSAE BULBUS.Thesis Sichuan Agricultural University chengdu-610000 chinapp2-10

36. Shi C, An S, Yao Z,Young CA,Panaccione DG, Lee ST,Schardl CL,Li C (2018) )Toxin-producing Epichloë bromicola strains symbiotic with the forage grass Elymus. dahuricus in China Mycologia 109(6):847-859

37. Tang JC, Chen JY (2011) Correlation between soil physical and chemical properties and effective components of Aconitum plants[J]. Journal of Southwest China Normal University(Natural Science Edition) 36(01):166-172

38. Tu YL (2019) Effects of Water Stress on the Physiology and M ain Secondary Metabolites of Tetrastigma hemsleyanum Diels et Gilg.Thesis Zhejiang A\&F University hangzhou-310000 chinapp2-4

39. Tanaka A, Takemoto D,Chujo T, Scott B (2021) Fungal endophytes of grasses.Curr Opin. Plant Biol Aug 15(4):462468

40. Vázquez-de-AldanaBR Romo MA,García-Ciudad, (2011)Infection with the fungal endophyte Epichlo festucae may alter the allelopathic potential of red fescue[J].Annals of Applied Biology159(2)

41. Wang JN, Hhuang YH,Mou ZM (2007) Research Progresson Flavonoid of the Plant Secondary Metabolites. Sericulture Science 33(3):499-505

42. Wang ZM Xie JH,Yang XH,Hu YL,Wang JLProgress on the isolation and detection methods and resistance of plant polyphenols.Guangdong Agricultural Science(06):69-73

43. Wang C, Lu J, Zhang S, Wang P (2011) )Effects of Pb stress on nutrient uptake and secondary metabolism in submerged macrophyte Vallisneria natans. EcotoxicolEnviron Saf 74:1297-1303

Page 10/15 
44. Wang D, Wan J, Fu T, Tang YM (2015) Isolation Purification and Characterization of Acid Phosphatase from Cilantro.food science 36(21):162-167

45. Wang S, Jiang DQ,KangCZ,Wan XF, Wang RS, Liang JW,Wang HY Li y,Wang TL,Huang LQ,Guo LP (2020)Core position of secondary metabolism of medicinal plants in ecological[J].Chinese Journal of traditional Chinese Medicine45(09):2002-2008

46. Xie AQ, Hong W, Wu CZ (2013) Effects of Endophytic Fungi on phosphorus uptake of Eucalyptus urophylla seedlings. Journal of Zhejiang agriculture and Forestry University 30(06):863-870

47. Xia C, Christensen MJ, Zhang XX (2018) Effect of Epichloë gansuensis endophyte and transgenerational effects on the water use efficiency nutrient and biomass accumulation of Achnatherum inebrians under soil water deficit. Plant Soil 424:555-571

48. Yan SJ, Liu YM,Sun LY,Lin XS,Luo HL,Lin H, Lin ZX,Sun HY (2021) Analysis of microbial diversity and enzyme activity of rhizosphere soil of Pennisetum giganteum(giant juncao) under different degree of saline-alkali stress[J/OL].Guangxi plants $\{3\}\{4\}\{5\}: 1-12$

49. Yan X (2011) The effects of environmental stresses on the compont and gene expression of flovoinds in trifoliate orange.Thesis Huazhong Agricultural University Wuhan-430000 chinapp28-30

50. Zhao FG (2004) Physiological ecology of plant stress[M]Beijing:Chemical Industry Press2004 7-86

51. Zhou FL Shou SY,Ye WZ,Lu GResearch progress of flavonoids in plant stress response.Journal of cell biology(01):39-44

52. Zhao J, Davis LC, Verpoorte R (2005) Elicitor signal transduction leading to production of plant secondary metabolites. Biotechnol Adv 23:283-333

53. Zhang GZ, He JJ, Yao XL, Chen XL,Guan J, Zhang YN,Mei X (2013) Effects of Refrigeration and Heat Treatment on Polyphenol oxidase Activity and Polyphenol Content of Water Chestnut[J]. Hubei Agricultural Sciences 52(19):47724775

\section{Figures}




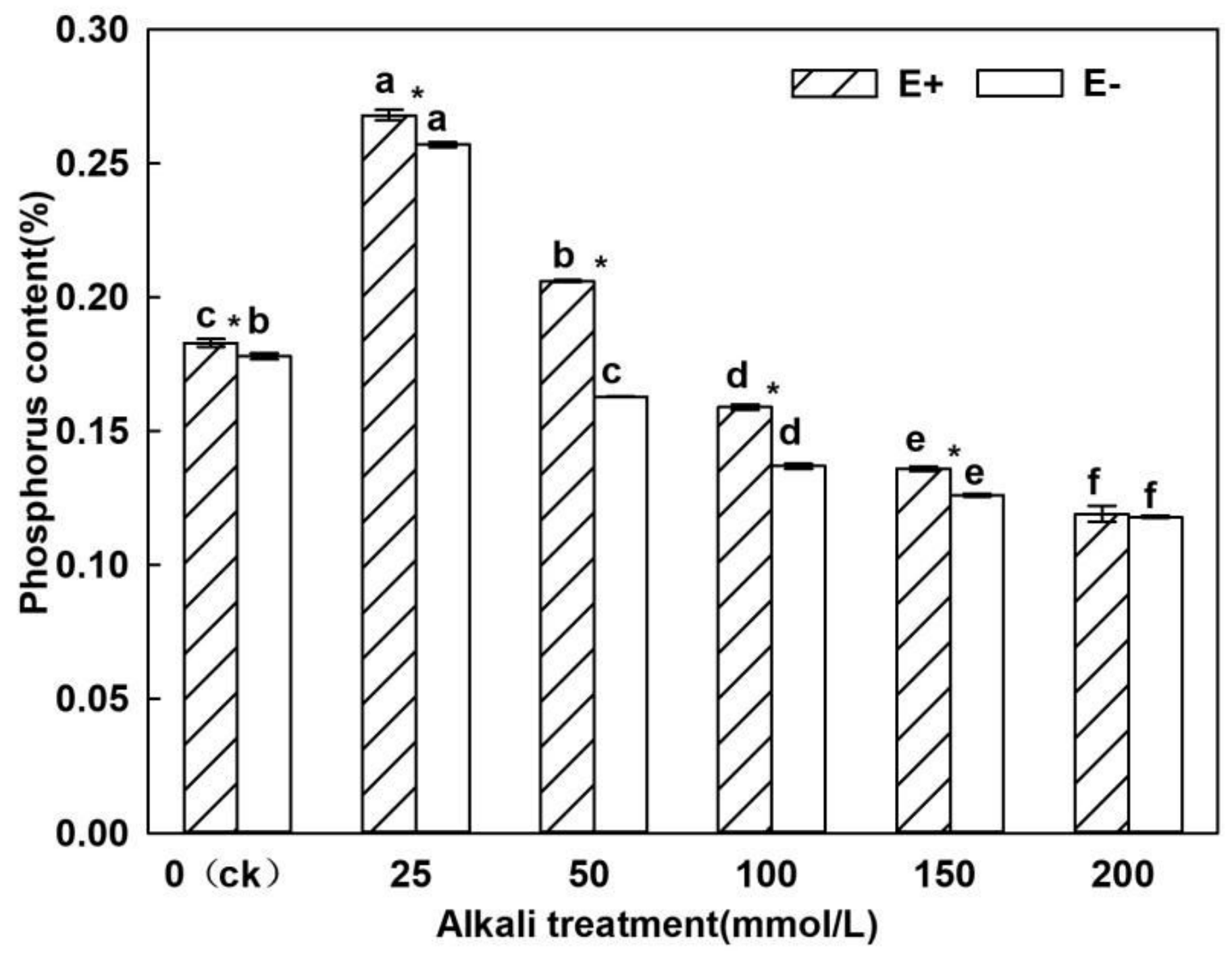

Figure 1

Phosphorus content in E + and E- Hordeum bogdanii roots under different concentrations of alkali treatments 


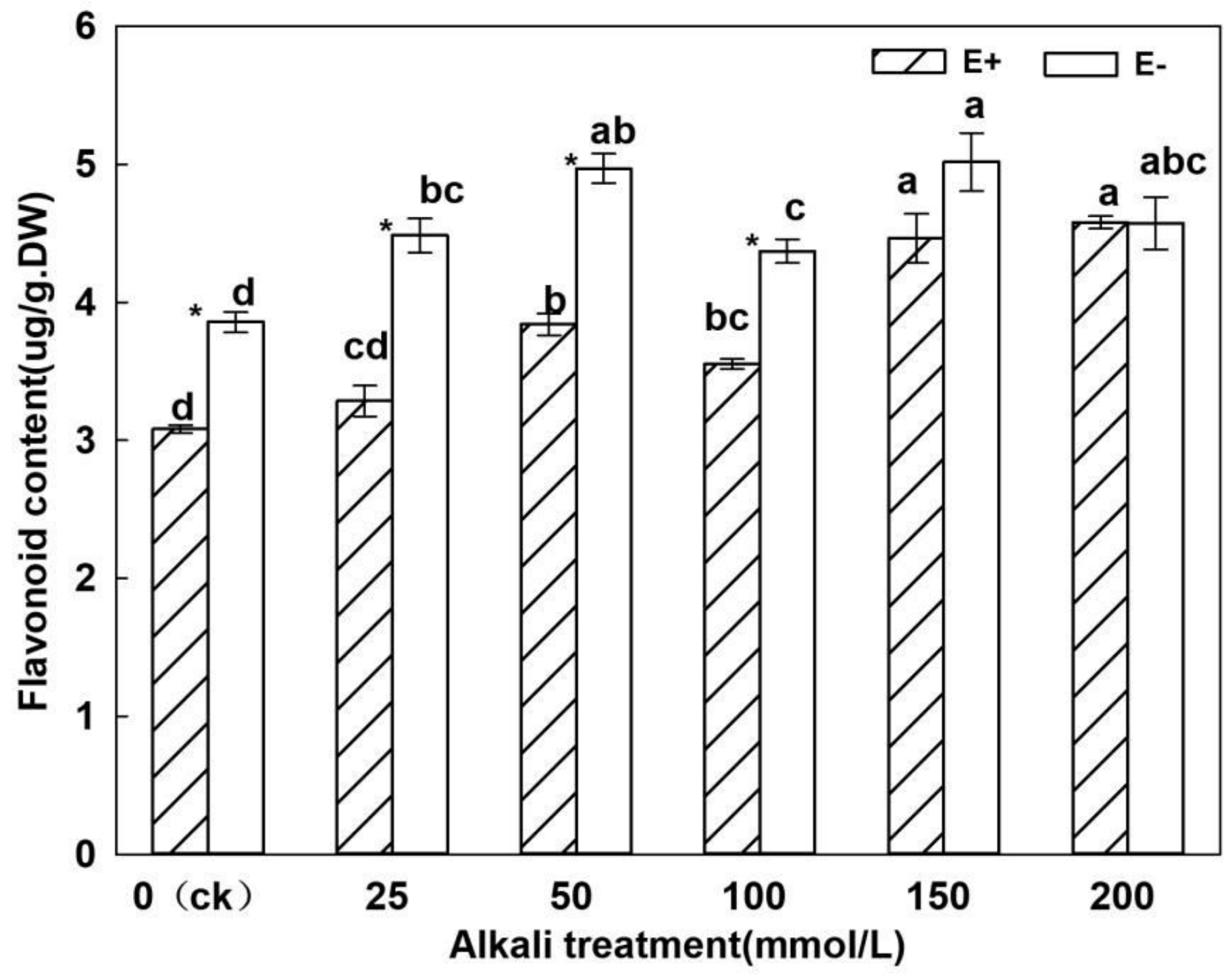

Figure 2

Flavonoid contents in stems of E + and E- Hordeum bogdanii under different concentrations of alkali treatments 

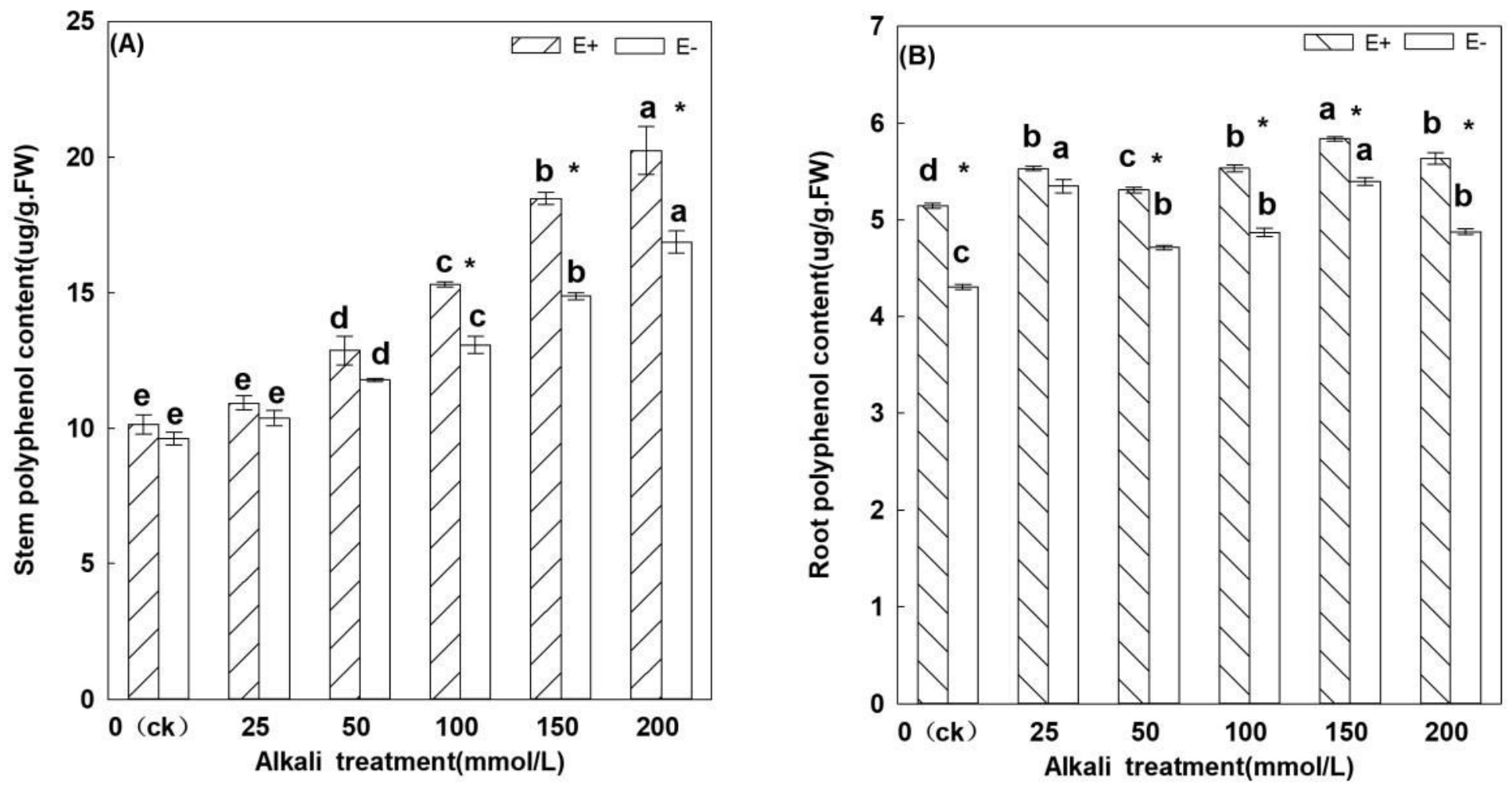

Figure 3

Polyphenol content in the stems and roots of $\mathrm{E}+$ and $\mathrm{E}$ - Hordeum bogdanii under different concentrations of alkali treatments ( $\mathrm{A}$ is the stem $\varangle \mathrm{B}$ is the root) 


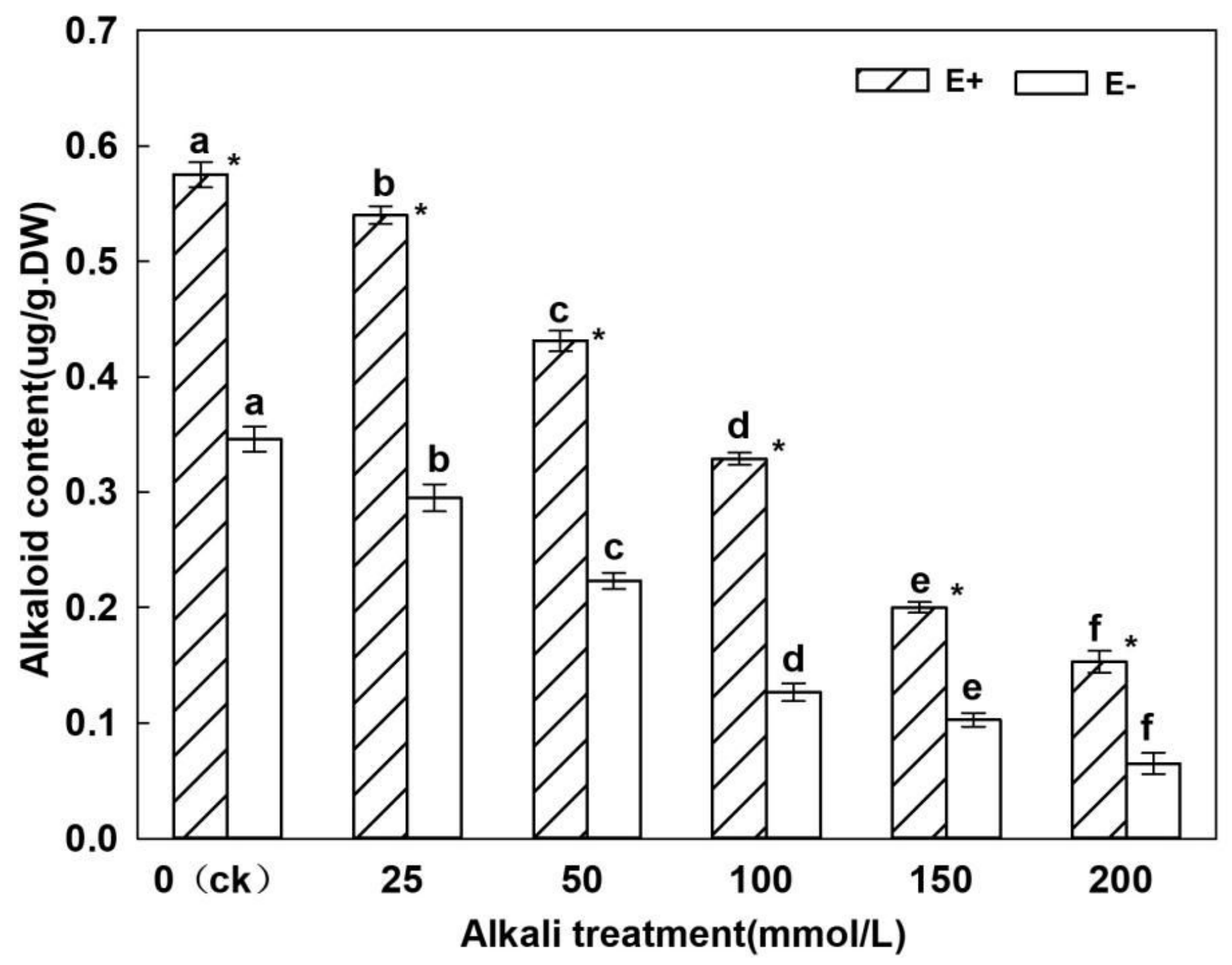

Figure 4

Alkaloid content in the stems of $\mathrm{E}+$ and $\mathrm{E}$ - Hordeum bogdanii under different concentrations of alkali treatments
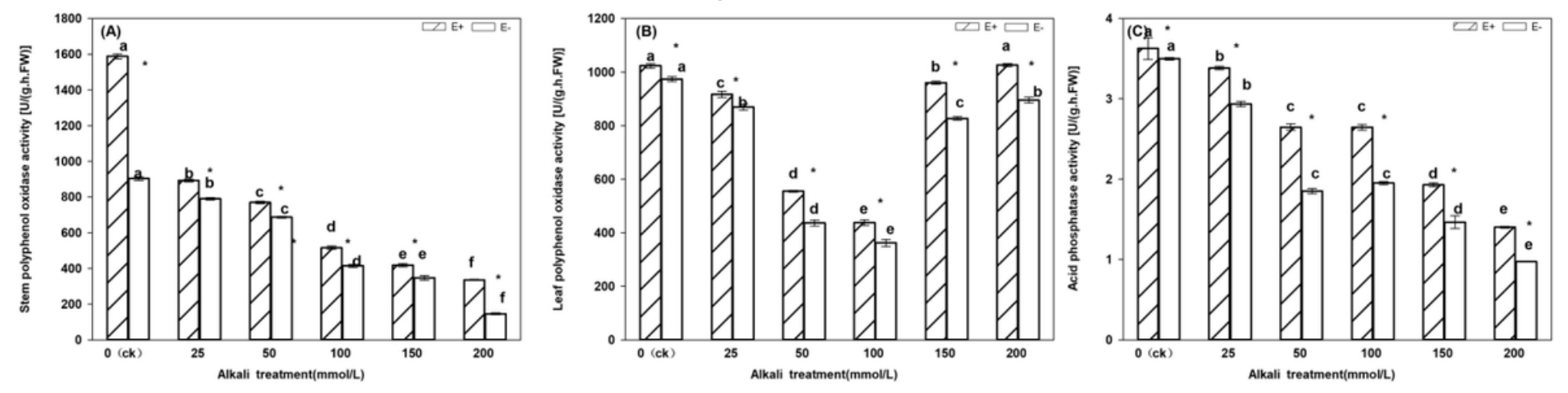

Figure 5

Polyphenol oxidase activity and acid phosphatase activity in stems and leaves of E+ and E- Hordeum bogdanii under different alkali treatments (picture $A$ is polyphenol oxidase activity in stem, picture $B$ is polyphenol oxidase activity in leaves, picture $\mathrm{C}$ is acid phosphatase activity) 